\title{
Dynamic monitor on psychological problems of medical aid teams in the context of Corona Virus Disease 2019: a multi-stage and multi-factor quantitative study
}

\section{Yanji Zhou}

School of public health囚Kunming Medical University

Chengyu Li

School of public health $₫$ Kunming Medical University

Xiyu Zhang

Research Center of Public Policy and Management, School of Health Management, Harbin Medical University

Li Xu

Department of Psychiatry, The Second Affiliated Hospital of Kunming Medical University

\section{Wenqing Miao}

Research Center of Public Policy and Management, School of Health Management, Harbin Medical University

Dingyun You

School of public health囚Kunming Medical University

Ye Li ( $\nabla$ liye8459@163.com )

Research Center of Public Policy and Management, School of Health Management, Harbin Medical University

\section{Research Article}

Keywords: mental health, anxiety, depression, medical staff, COVID-19, China

Posted Date: February 19th, 2021

DOI: https://doi.org/10.21203/rs.3.rs-209483/v1

License: (c) (i) This work is licensed under a Creative Commons Attribution 4.0 International License. Read Full License

Version of Record: A version of this preprint was published at BMC Public Health on August 3rd, 2021. See the published version at https://doi.org/10.1186/s12889-021-11479-0. 


\section{Abstract}

Background: In order to explore the psychological status and vulnerability characteristics of medical staff with the progress of the epidemic.

Methods: This study investigated the prevalence of mental problems of 2748 medical staff in four stages. PHQ-9, GAD-7, SSS, Pittsburgh sleep quality index and PCL-C were used for the psychological evaluation, and univariate logistic standardized analysis and multivariate logistic regression for data analysis.

Results: The prevalence of mental problems were observed statistically significant difference. In stage 1, mild anxiety and mild depression reached the highest value of $41.4 \%$ and $40.72 \%$ respectively. Between March 4 and March 17 that of mild depression rose from 16.07\% to 26.7\%, and between March 17 and March 26 the prevalence of mild anxiety increased from $17.28 \%$ to $20.02 \%$. Female, unmarried, working in Wuhan are the risk factors of mental health of medical staff $(P<0.05)$.

Conclusion: The psychological status of the medical staff has changed dynamically. Stage 1, the latter period of Stage 2 and Stage 3 are the high-risk stages. Female,unmarried is the dangerous characteristics of psychological vulnerability.

\section{Introduction}

At the end of 2019, when all the Chinese cities were immersed in the peaceful atmosphere of the Traditional New Year, it was never expected that a potentially new malignant infectious disease was spreading quietly. Wuhan City, a prosperous metropolis with over ten million populations, became the target of the outbreak and was shrouded in the panic by unknown viral pneumonia. The Chinese government quickly launched a first-level emergency response plan and issued warning signals to the world. On January 11, 2020, the World Health Organization named this pandemic as Corona Virus Disease 2019 (COVID-2019), declaring a new round of confrontation between humans and infectious disease on a global scale. The cumulative number of confirmed cases increased from 291 on January 21 to 24,325 on February 4. Around February 15, China's prevention and control of the epidemic began to achieve results. The number of new confirmed cases in China's epidemic began to decline dramatically, and achieved zero case reported for the first time on March 19.

In such a disastrous health emergency situation, Wuhan's medical health system had been greatly tested, nearly 42000 medical staff all over the country were successively sent to Wuhan with medical resources. Facing with a large number of fever patients and critically ill patients, the medical staffs were under huge physical and psychological pressure. Medical staffs must not only be engaged in the clinical treatment, nursing and psychological counseling of patients with COVID-19, but also deal with the pressure due to shortage of materials, manpower and unknown areas of disease and epidemic. Series of studies has confirmed that medical staffs are more vulnerable to suffer psychological problem during the public health emergency period. ${ }^{[1,2]}$

As demonstrated in a survey of first-line medical staff from Gansu Province in this COVID-19 epidemic, negative psychological symptoms such as anxiety and depression were more likely occur to medical staff, which was twice as likely to show anxiety or depression as the non-clinical staff ${ }^{[3]}$. Moreover, the occupation, marital status and education level of the medical staff were confirmed as the determinants for these psychological symptoms. However, to our knowledge, almost all of these literature stayed in the cross-sectional study, researches on multiperiods comparison of the psychological status of first-line medical staff is still in a relative blank stage. Dynamic 
monitoring the psychological status of the medical staff is significant to target the characteristics of vulnerable groups and further make precise intervention plans in the catastrophic health emergencies period, which is crucial not only for the work performance of the medical staff but also for the health outcome of the residents in the whole country. Accordingly, our study is to evaluate the psychological status of medical staff for 4 key time points in the COVID-19 epidemic. By multi-dimensional assessment, the intervention priorities of vulnerable group will be screened accurately, which provides good experience for other countries still in the pandemic storm .

\section{Methods}

\section{Design and sample procedure}

A total of 2748 medical staff were investigated at four stages (five time points): Stage 1(February 10 - February 20 : the beginning of the epidemic ), Stage 2 (March 3 - March 5, March 15 - March 18: peak of the epidemic), Stage 3 (March 23 - March 28: returning time from Hubei Province), and Stage 4 (April 1 - April 7: time after isolation and recuperation). The questionnaire included basic demographic data (gender, age, marital status, educational background, occupation, Department, etc.), current physical condition and working place during the period of aiding Hubei Province. All the data was collected via online survey agency (Wenjuanxing www.wjx.cn). The depression level was assessed by PHQ-9 depression screening scale, anxiety level was assessed by GAD-7 anxiety screening scale, and physical disorder was assessed by Somatization Symptom Checklist (SSS) and Pittsburgh sleep quality index was used for the evaluation of sleep quality, and self rating scale for post-traumatic stress disorder (PCL-C) was used for evaluation of post-traumatic stress disorder.

\section{Statistical analysis}

In this study, the statistical analysis was implemented by R 3.6.2 software, and the graphs were drawn with R 3.6.2 software ggplot2 package. After the data cleaning, a total of 2748 medical staffs participated in the questionnaire at five time points were included as the total number of observation cases. According to the depression and anxiety scale, the symptoms of all participants were divided into three level (none, mild, moderate and severe). Based on the literature review, determinants of depression and anxiety included: gender, occupation, age, marital status, educational background, workplace during the epidemic. Logistic regression analysis, univariate logistic stratified analysis (time stratification) and multivariate logistic regression analysis were used to analyze the correlation between depression (anxiety) level. We establishes the significance of two-sided test is $\mathrm{P}<0.05$.

In univariate logistic stratified analysis, time was used as stratified variable. For the variable of "working place during the epidemic": the option of "working in regions outside Hubei Province" could not be stratified because of too many missing values; the option of "working in Wuhan" and "working in regions in Hubei Province except Wuhan" were all based on the medical aid team's isolation and recuperation time (Stage 4) as the reference level. For the variable of "occupation", the option of "other" was based on the time when the medical team returned to the Yunnan Province (Stage 3); the other options were all based on the reference level at the beginning of the epidemic (Stage 1) .

In order to explore the relationship between the different time nodes of epidemic development and the degree of depression and anxiety of medical staff, the multi-factor logistic regression analysis was used. 2748 medical staff were selected as the observation objects, and the independent variables were different time nodes (February 10February 20, March 3- March 5, March 15- March 18, March 23- March 28, April 1- April 7), depression level (no depression, mild depression, moderate and severe depression) and anxiety (no anxiety, mild anxiety, moderate and severe anxiety) of medical staff. Taking Stage 1 (February 10- February 20) as the reference level, the ORvalue (95\% 
$\mathrm{Cl}$ ) and $\mathrm{P}$ value were observed during Stage 2 (March 3- March 5, March 15- March 18), Stage 3 (March 23- March 28), and Stage 4 (April 1- April 7). Model 1 was a single factor Logistic regression model without adjusting any variables; model 2 adjusted some variables (gender, age and occupation of medical staff); model 3 adjusted all variables (gender, age, occupation, marital status and education level) to control the bias caused by confounding factors.

\section{Results}

\section{Basic information}

2748 participants were investigated in all the four stages. At all stages of the study, we investigated 2748 subjects. In Stage 1, 180 (40.82\%) doctors and 261 (59.18\%) nurses were investigated. In Stage 3, 264 (24.93\%) doctors and $773(73.0 \%)$ nurses were investigated. In Stage 4, 254 (25.43\%) doctors and 721 (72.17\%) nurses participated in the survey..442 medical staffs working outside Hubei Province were investigated at Stage 1(the beginning of the epidemic), which was the main period of investigation for medical staff working outside Hubei Province. From Stage 3 on, medical staff working in Hubei Province began to be investigated. In Stage 3, 601 (57.46\%) medical workers were in Wuhan and 444 (42.45\%) medical workers were in other cities of Hubei Province. It should be noted that female medical staff were larger than male, especially in Stage 1, which investigated 362 (81.90\%) women and 80 (18.10\%) men. In addition, the population we investigated mainly consists of medical workers aged 21-40. In Stage $3,382(36.17 \%)$ medical workers in their 20 s and 432 (40.91\%) medical workers in their 30 s were investigated, which is the most significant stage (Table 1). 
Table 1

Table of research object composition

\begin{tabular}{|c|c|c|c|c|c|c|c|}
\hline \multirow[t]{3}{*}{ Variables } & \multicolumn{7}{|l|}{ Date } \\
\hline & \multirow{2}{*}{$\begin{array}{l}\text { Stage } 1 \\
(2.10-2.20)\end{array}$} & \multirow{2}{*}{$\begin{array}{l}\text { Stage } 2 \\
(3.3-3.5)\end{array}$} & \multirow{2}{*}{$\begin{array}{l}\text { Stage } 2 \\
(3.15-3.18)\end{array}$} & \multirow{2}{*}{\multicolumn{2}{|c|}{$\begin{array}{l}\text { Stage } 3 \\
(3.23-3.28)\end{array}$}} & \multirow{2}{*}{\multicolumn{2}{|c|}{$\begin{array}{l}\text { Stage } 4 \\
(4.1-4.7)\end{array}$}} \\
\hline & & & & & & & \\
\hline \multicolumn{8}{|l|}{ Work Location } \\
\hline Wuhan & & & & 601 & $(57.46 \%)$ & 577 & $(58.34 \%)$ \\
\hline $\begin{array}{l}\text { Regions } \\
\text { outside Hubei } \\
\text { Province }\end{array}$ & $442 \quad(100.00 \%)$ & & & 1 & $(0.10 \%)$ & 1 & $(0.10 \%)$ \\
\hline $\begin{array}{l}\text { Regions of } \\
\text { Hubei } \\
\text { Province } \\
\text { except Wuhan }\end{array}$ & & & & 444 & $(42.45 \%)$ & 411 & $(41.56 \%)$ \\
\hline
\end{tabular}

Sex

$\begin{array}{lllllllllll}\text { Male } & 80 & (18.10 \%) & 16 & (28.57 \%) & 70 & (36.65 \%) & 298 & (28.14 \%) & 294 & (29.40 \%)\end{array}$ $\begin{array}{lllllllllll}\text { Female } & 362 & (81.90 \%) & 40 & (71.43 \%) & 121 & (63.35 \%) & 761 & (71.86 \%) & 706 & (70.60 \%)\end{array}$ Occupation

$\begin{array}{lllllllllll}\text { Doctor } & 180 & (40.82 \%) & 18 & (32.14 \%) & 70 & (36.65 \%) & 264 & (24.93 \%) & 254 & (25.43 \%) \\ \text { Nurse } & 261 & (59.18 \%) & 38 & (67.86 \%) & 120 & (62.83 \%) & 773 & (72.99 \%) & 721 & (72.17 \%)\end{array}$

$\begin{array}{lllllllllll}\text { Nurse } & 261 & (59.18 \%) & 38 & (67.86 \%) & 120 & (62.83 \%) & 773 & (72.99 \%) & 721 & (72.17 \%) \\ \text { Other } & & & & & 1 & (0.52 \%) & 22 & (2.08 \%) & 24 & (2.40 \%)\end{array}$

Age

$\begin{array}{lllllllllll}\mathbf{2 1 - 3 0} & 185 & (41.86 \%) & 20 & (35.71 \%) & 87 & (45.55 \%) & 382 & (36.17 \%) & 352 & (35.24 \%) \\ \mathbf{3 1 - 4 0} & 149 & (33.71 \%) & 15 & (26.79 \%) & 67 & (35.08 \%) & 432 & (40.91 \%) & 410 & (41.04 \%) \\ \mathbf{4 1 - 5 0} & 83 & (18.78 \%) & 20 & (35.71 \%) & 35 & (18.32 \%) & 218 & (20.64 \%) & 209 & (20.92 \%) \\ \mathbf{5 1 - 6 0} & 20 & (4.52 \%) & & & 2 & (1.05 \%) & 23 & (2.18 \%) & 28 & (2.80 \%) \\ >\mathbf{6 0} & 5 & (1.13 \%) & 1 & (1.79 \%) & & & 1 & (0.09 \%) & & \end{array}$

Marital Status

$\begin{array}{lllllllllll}\text { Unmarried } & 115 & (26.02 \%) & 14 & (25.00 \%) & 65 & (34.03 \%) & 289 & (27.29 \%) & 266 & (26.60 \%) \\ \text { Married } & 317 & (71.72 \%) & 39 & (69.64 \%) & 122 & (63.87 \%) & 734 & (69.31 \%) & 700 & (70.00 \%) \\ \text { Other } & 10 & (2.26 \%) & 3 & (5.36 \%) & 4 & (2.09 \%) & 36 & (3.40 \%) & 34 & (3.40 \%)\end{array}$

\section{Educational}

background

$\begin{array}{lllllllllll}\text { Undergraduate } & 292 & (66.06 \%) & 46 & (82.14 \%) & 140 & (73.30 \%) & 772 & (72.90 \%) & 730 & (73.00 \%)\end{array}$

$\begin{array}{lllllllllll}\text { Graduate } & 67 & (15.16 \%) & 1 & (1.79 \%) & 14 & (7.33 \%) & 103 & (9.73 \%) & 87 & (8.70 \%)\end{array}$

$\begin{array}{lllllllllll}\text { Middle school } & 83 & (18.78 \%) & 9 & (16.07 \%) & 37 & (19.37 \%) & 184 & (17.37 \%) & 183 & (18.30 \%)\end{array}$ 


\section{Anxiety}

According to our survey data, there was a statistical correlation between anxiety level and the occurrence and development of epidemic diseases $\left(X^{2}=206.394, P<0.0001\right)$. In Stage 1 , the prevalence of moderate and severe anxiety was $7.47 \%$ and kept decreasing, which gradually decreased to $2.46 \%$ in Stage 3 and even to $0.9 \%$ in Stage 4 . The prevalence of mild anxiety was $41.4 \%$ in Stage 1, with the downward trend to $17.28 \%$ in Stage 2 and finally to $12.4 \%$ in Stage 4 . In all subgroups, most of the respondents were those without anxiety symptoms ,and the proportion of respondents with moderate and severe anxiety was the smallest. Further stratified analysis showed that various factors had a certain impact on the anxiety variables of medical staff. Compared with working in Wuhan City, working in regions outside Wuhan especially outside Hubei province was more likely to have a higher level of anxiety $(\mathrm{OR}, 4.566 ; 95 \% \mathrm{Cl}, 3.603-5.786)$. Univariate logistic regression analysis showed that gender was associated with anxiety (male medical staff vs female medical staff $(\mathrm{OR}, 0.639 ; 95 \% \mathrm{Cl}, 0.517-0.79)$.Further, compared with 21-30-years-old young medical staff, medical staff over 60 years old were inclined to a greater risk of anxiety (OR,3.967;95\% Cl,0.955-16.473). And married (OR,1.982;95\%Cl,1.047,3.750) and unmarried $(\mathrm{OR}, 2.394 ; 95 \% \mathrm{Cl}, 1.250,4.585)$ medical workers have more possibilities to suffer from anxiety problems than medical workers with other marital status. In addition, compared to the undergraduate education group,the graduates' educational background group was more likely to suffer anxiety. (OR,1.330;95Cl,1.002,1.767) (Table 2). 
Table 2

Factors influencing anxiety level

\begin{tabular}{|c|c|c|c|c|c|c|c|}
\hline Variables & & $\begin{array}{l}\text { No anxiety } \\
(N=1924)\end{array}$ & $\begin{array}{l}\text { Mild } \\
\text { anxiety } \\
(\mathrm{N}=656)\end{array}$ & $\begin{array}{l}\text { Moderate } \\
\text { and } \\
\text { Severe } \\
\text { anxiety } \\
(\mathrm{N}=168)\end{array}$ & & $\mathbf{P}$ & OR(95\%Cl) \\
\hline Time & & & & & 206.3935 & $<.0001$ & \\
\hline $\begin{array}{l}\text { Stage } 1(2.10- \\
2.20)\end{array}$ & 442 & $226(51.13)$ & 183(41.4) & $33(7.47)$ & l & / & 1 \\
\hline $\begin{array}{l}\text { Stage } 2 \text { (3.3- } \\
3.5)\end{array}$ & 56 & $44(78.57)$ & $12(21.43)$ & $0(0)$ & 0.2995 & 0.5842 & $\begin{array}{l}0.276(0.142- \\
0.537)\end{array}$ \\
\hline $\begin{array}{l}\text { Stage } 2 \text { (3.15- } \\
3.18)\end{array}$ & 191 & 154(80.63) & $33(17.28)$ & $4(2.09)$ & 2.2291 & 0.1354 & $0.25(0.167-0.374)$ \\
\hline $\begin{array}{l}\text { Stage } 3(3.23- \\
3.28)\end{array}$ & 1059 & $821(77.53)$ & 212(20.02) & $26(2.46)$ & 0.3158 & 0.5741 & $\begin{array}{l}0.302(0.239- \\
0.381)\end{array}$ \\
\hline $\begin{array}{l}\text { Stage } 4 \text { (4.1- } \\
4.7)\end{array}$ & 1000 & $867(86.7)$ & $124(12.4)$ & $9(0.9)$ & 41.4921 & $<.0001$ & $\begin{array}{l}0.159(0.123- \\
0.206)\end{array}$ \\
\hline Work Location & & & & & 181.0609 & $<.0001$ & \\
\hline Wuhan City & 1178 & $974(82.68)$ & 186(15.79) & $18(1.53)$ & / & / & 1 \\
\hline $\begin{array}{l}\text { Regions } \\
\text { outside Hubei } \\
\text { Province }\end{array}$ & 444 & $228(51.35)$ & 183(41.22) & $33(7.43)$ & 177.7324 & $<.0001$ & $\begin{array}{l}4.566(3.603- \\
5.786)\end{array}$ \\
\hline $\begin{array}{l}\text { Regions of } \\
\text { Hubei } \\
\text { Province } \\
\text { except Wuhan }\end{array}$ & 855 & 693(81.05) & 147(17.19) & $15(1.75)$ & 37.4884 & $<.0001$ & $\begin{array}{l}1.117(0.889- \\
1.402)\end{array}$ \\
\hline \multicolumn{8}{|l|}{ Gender } \\
\hline Male & 758 & 624(82.32) & 118(15.57) & $16(2.11)$ & 17.1784 & $<.0001$ & $0.639(0.517-0.79)$ \\
\hline Female & 1990 & 1488(74.77) & $446(22.41)$ & $56(2.81)$ & l & / & 1 \\
\hline Occupation & & & & & 0.8661 & 0.6485 & \\
\hline Doctor & 786 & 614(78.12) & 148(18.83) & $24(3.05)$ & / & / & 1 \\
\hline Nurse & 1913 & $1459(76.27)$ & 409(21.38) & $45(2.35)$ & 0.2209 & 0.6384 & $1.097(0.9-1.338)$ \\
\hline Other & 47 & $37(78.72)$ & $7(14.89)$ & $3(6.38)$ & 0.0114 & 0.9151 & $\begin{array}{l}1.009(0.498- \\
2.044)\end{array}$ \\
\hline Age & & & & & 10.7989 & 0.001 & \\
\hline $21-30$ & 1026 & $750(73.1)$ & $249(24.27)$ & $27(2.63)$ & / & / & 1 \\
\hline
\end{tabular}




\begin{tabular}{|c|c|c|c|c|c|c|c|}
\hline Variables & & $\begin{array}{l}\text { No anxiety } \\
(\mathrm{N}=1924)\end{array}$ & $\begin{array}{l}\text { Mild } \\
\text { anxiety } \\
(\mathrm{N}=656)\end{array}$ & $\begin{array}{l}\text { Moderate } \\
\text { and } \\
\text { Severe } \\
\text { anxiety } \\
(\mathrm{N}=168)\end{array}$ & & $\mathbf{P}$ & $\mathrm{OR}(95 \% \mathrm{Cl})$ \\
\hline $31-40$ & 1073 & $843(78.56)$ & 199(18.55) & $31(2.89)$ & 5.4765 & 0.0193 & $\begin{array}{l}0.752(0.615- \\
0.918)\end{array}$ \\
\hline $41-50$ & 565 & $458(81.06)$ & $97(17.17)$ & $10(1.77)$ & 9.801 & 0.0017 & $\begin{array}{l}0.637(0.496- \\
0.819)\end{array}$ \\
\hline $51-60$ & 73 & $55(75.34)$ & $16(21.92)$ & $2(2.74)$ & 0.6886 & 0.4066 & $\begin{array}{l}0.895(0.517- \\
1.547)\end{array}$ \\
\hline$>60$ & 7 & $3(42.86)$ & $3(42.86)$ & $1(14.29)$ & 4.7798 & 0.0288 & $\begin{array}{l}3.967(0.955- \\
16.473)\end{array}$ \\
\hline Marital Status & & & & & 8.8586 & 0.0119 & \\
\hline Unmarried & 749 & $553(73.83)$ & 179(23.9) & $17(2.27)$ & 8.455 & 0.0036 & $2.394(1.250,4.585)$ \\
\hline Married & 1912 & $1483(77.56)$ & $376(19.67)$ & $53(2.77)$ & 2.0094 & 0.1563 & $1.982(1.047,3.750)$ \\
\hline Other & 87 & $76(87.36)$ & $9(10.34)$ & $2(2.3)$ & / & I & 1 \\
\hline $\begin{array}{l}\text { Educational } \\
\text { Background }\end{array}$ & & & & & 3.8925 & 0.1428 & \\
\hline Undergraduate & 1980 & 1534(77.47) & $396(20)$ & $50(2.53)$ & / & / & 1 \\
\hline Graduate & 272 & 197(72.43) & $63(23.16)$ & $12(4.41)$ & 3.3847 & 0.0658 & $1.330(1.002,1.767)$ \\
\hline Middle school & 496 & $381(76.81)$ & 105(21.17) & 10(2.02) & 0.7725 & 0.3795 & $1.030(0.816,1.301)$ \\
\hline
\end{tabular}

Obviously, compared with the medical staff who felt mild anxiety, the medical staff who felt moderate or severe anxiety were only a small part of the respondents. As shown in Fig. 1, the prevalence of mild anxiety in male has been decreasing all the time, but the prevalence of mild anxiety in women has increased slightly from $17.5 \%$ (the former period of Stage 2) to $21.81 \%$ (Stage 3) (March 4 to March 26). In Stage 1, both the male and female medical staff were found to suffer the highest prevalence of mild anxiety with $42.82 \%$ for female medical staff, which was $7.82 \%$ higher than that of male. Moreover, the prevalence of moderate and severe anxiety of medical workers of different genders were highest to $5 \%$ for male medical works and $8.01 \%$ for female medical workers, then decreased to the lowest prevalence in the former period of Stage 2. Although this prevalence slightly increased to $2.63 \%$ for female and $2.01 \%$ for male, it decreased to $0.57 \%$ and $1.7 \%$ for female and for male respectively in Stage 4 .

For nurses, the prevalence of mild anxiety increased from $18.33 \%$ (the latter period of Stage 2) to $22.38 \%$ (Stage 3), although the changing trends of anxiety of doctors and nurses are similarly downward. Moreover, the main difference of moderate and severe anxiety is that the prevalence of doctors decreased from $2.86 \%$ (the latter period of Stage 2) to $1.89 \%$ (Stage 3), while that of nurses increased from $1.67 \%$ (the latter period of Stage 2) to $2.59 \%$ (Stage 3) (Fig. 2).

In Fig. 3, from the first sampling (Stage 1) to March 17 (the latter period of Stage 2), the prevalence of mild anxiety in graduate education background group, undergraduate education background group and middle school education background group decreased by $39.13 \%, 27.04 \%$ and $6.09 \%$, respectively. The main difference of the prevalence of moderate and severe anxiety of medical staff with different educational background occured between Stage 3 and 
Stage 4. The prevalence of moderate and severe anxiety of medical staff with graduate education increased from 0.97-1.15\% between Stage 3 and Stage 4, while on the contrary, the prevalence of moderate and severe anxiety of medical staff with undergraduate education background decreased from $2.46-1.1 \%$ during the same period.

Although the prevalence of mild anxiety of married and unmarried medical staff increased by $3.23 \%$ and $4.57 \%$ respectively only between the latter period of Stage 2 and Stage 3, while the prevalence of medical staff with other marital status decreased sharply from $25-8.33 \%$. The prevalence of moderate and severe anxiety of medical staff in different marital status groups was similar, but there was one point that should be paid attention to widely that between the latter period of Stage 2 and Stage 3, the prevalence of moderate and severe anxiety of married medical staff decreased by $0.01 \%$, while that of unmarried medical staff increased by $0.88 \%$ (Fig. 4 ).

\section{Depression}

According to our survey data, there was a statistical relationship between the level of depression and the occurrence and development of the pandemic $\left(c^{2}=181.739, P<0.0001\right)$. The prevalence of moderate and severe anxiety in Stage 1 was $14.48 \%$, which continued to decline to $2.09 \%$ in Stage 2 and increased to $6.61 \%$ in Stage 3, but finally decline to $3 \%$ in Stage 4 . The highest prevalence of mild anxiety of depression was $40.72 \%$ in Stage 1 , and then decreased to 0.39 times of the original in the former period of Stage 2. However, from the latter period of Stage 2 on, it rose to $26.7 \%$ in the latter period of Stage 2 temporarily, then continued to decline to $17.4 \%$ in Stage 4 .

In all subgroups, the proportion of moderate and severe depression was less than that of mild depression. Further stratified analysis showed that all kinds of variables of interest also had a certain impact on the depression variables of medical staff. Compared with working in Wuhan, working outside Wuhan, especially in regions outside Hubei province, is more likely to reach higher depression level (OR,3.846;95\% $\mathrm{Cl}, 3.079-4.804)$. Regression analysis showed that gender was associated with depression (male versus female; $0 R, 0.676 ; 95 \% \mathrm{Cl}, 0.581-0.786$ ). Moreover, the risk of depression was higher in the medical staff over 60 years old than in the young medical staff aged 21-30 years old (OR,2.032;95\% Cl,0.494-8.357). Unmarried medical staff were more at risk of depression than married medical staff (OR,1.325;95\% Cl, 1.109-1.583), while those with other marital status were less at risk of depression than married medical staff (OR,0.858;95\% Cl,0.526-1.399). In addition, compared with the undergraduate education background group, the graduate education background group is more likely to produce a higher prevalence of anxiety (OR,1.120;95Cl,0.857-1.465) (Table 3).

Table 3 Factors influencing depression level 


\begin{tabular}{lccccc}
\hline Variables & $\begin{array}{c}\text { No } \\
\text { depression } \\
(\mathbf{N}=1924)\end{array}$ & $\begin{array}{c}\text { Mild } \\
\text { depression } \\
(\mathbf{N}=656)\end{array}$ & $\begin{array}{c}\text { Moderate and Severe } \\
\text { depression } \\
(\mathbf{N}=168)\end{array}$ & $x^{2} / \mathrm{F} / 2$ & $\mathrm{P}$ \\
OR(95\%CI)
\end{tabular}

\begin{tabular}{|c|c|c|c|c|c|c|c|}
\hline \multicolumn{4}{|l|}{ Time } & \multicolumn{4}{|c|}{$181.7389<.0001$} \\
\hline Stage $1(2.10-2.20)$ & 442 & $198(44.8)$ & $180(40.72)$ & $64(14.48)$ & l & / & 1 \\
\hline Stage $2(3.3-3.5)$ & 56 & $47(83.93)$ & $9(16.07)$ & $0(0)$ & 6.4561 & 0.011 & $0.151(0.072-0.317)$ \\
\hline Stage $2(3.15-3.18)$ & 191 & $136(71.2)$ & $51(26.7)$ & $4(2.09)$ & 0.016 & 0.899 & $0.315(0.219-0.451)$ \\
\hline Stage $3(3.23-3.28)$ & 1059 & $747(70.54)$ & $242(22.85)$ & $70(6.61)$ & 0.5384 & 0.463 & $0.345(0.277-0.43)$ \\
\hline Stage $4(4.1-4.7)$ & 1000 & 796(79.6) & $174(17.4)$ & $30(3)$ & 17.6115 & $<.00$ & $0.207(0.164-0.262)$ \\
\hline Work Location & & & & & 153.0325 & $<.00$ & \\
\hline Wuhan & 1178 & $896(76.06)$ & $235(19.95)$ & $47(3.99)$ & / & / & 1 \\
\hline Regions outside Hubei Province & 444 & $200(45.05)$ & $180(40.54)$ & $64(14.41)$ & 148.1195 & $<.00$ & $3.846(3.079-4.804)$ \\
\hline
\end{tabular}

Regions of Hubei Province except 855 628(73.45) 177(20.7)

$50(5.85)$

$29.5819<.00011 .168(0.955-1.427)$ Wuhan

\begin{tabular}{|c|c|c|c|c|c|}
\hline Gender & & & & 30.6478 & $<.0001$ \\
\hline Male & $758 \quad 592(78.1)$ & $128(16.89)$ & $38(5.01)$ & 30.6478 & $<.00010 .676(0.581-0.786)$ \\
\hline Female & $19901332(66.93)$ & $528(26.53)$ & $130(6.53)$ & l & 1 \\
\hline Occupation & & & & 2.3018 & 0.3163 \\
\hline Doctor & $786568(72.26)$ & $169(21.5)$ & $49(6.23)$ & l & 1 \\
\hline Nurse & $19131322(69.11)$ & $475(24.83)$ & $116(6.06)$ & 0.0737 & $0.7861 .148(0.957-1.378)$ \\
\hline Other & $47 \quad 32(68.09)$ & $12(25.53)$ & $3(6.38)$ & 0.1399 & $0.70841 .205(0.644-2.252)$ \\
\hline Age & & & & 20.9162 & 0.0003 \\
\hline $21-30$ & $1026673(65.59)$ & $276(26.9)$ & $77(7.5)$ & l & 1 \\
\hline $31-40$ & $1073764(71.2)$ & $251(23.39)$ & $58(5.41)$ & 0.9052 & $0.34140 .765(0.638-0.919)$ \\
\hline $41-50$ & $565 \quad 424(75.04)$ & $115(20.35)$ & $26(4.6)$ & 4.0822 & $0.04330 .631(0.502-0.792)$ \\
\hline $51-60$ & $73 \quad 56(76.71)$ & $13(17.81)$ & $4(5.48)$ & 2.5912 & $0.10750 .585(0.337-1.017)$ \\
\hline$>60$ & $4(57.14)$ & $1(14.29)$ & $2(28.57)$ & 2.0123 & $0.1562 .032(0.494-8.357)$ \\
\hline Marital Status & & & & 10.5116 & 0.0052 \\
\hline Unmarried & $749492(65.69)$ & $198(26.44)$ & $59(7.88)$ & 6.0112 & $0.01421 .325(1.109,1.583)$ \\
\hline Married & $19121368(71.55)$ & $436(22.8)$ & $108(5.65)$ & l & 1 \\
\hline Other & $87 \quad 64(73.56)$ & $22(25.29)$ & $1(1.15)$ & 1.3968 & $0.23730 .858(0.526,1.399)$ \\
\hline Educational Background & & & & 1.19 & 0.5516 \\
\hline Undergraduate & $19801388(70.1)$ & $466(23.54)$ & $126(6.36)$ & l & 1 \\
\hline Graduate & $272184(67.65)$ & $69(25.37)$ & $19(6.99)$ & 1.0826 & $0.29811 .120(0.857,1.465)$ \\
\hline Middle school & $496 \quad 352(70.97)$ & $121(24.4)$ & $23(4.64)$ & 0.988 & $0.32020 .940(0.758,1.165)$ \\
\hline
\end{tabular}

The prevalence of mild anxiety of female medical staff decreased by $5.91 \%$ and $7.22 \%$ respectively between the latter period of Stage 2 and Stage 3 and between Stage 3 and Stage 4, while that of male medical staff decreased by $2.46 \%$ and $0.8 \%$ respectively. Between Stage 3 and Stage 4 , the prevalence of moderate and severe anxiety in male and female medical staff decreased by $1.3 \%$ and $4.53 \%$ respectively, which indicated that women responded more intensely to the changing variables of interest in this stage (Fig. 5). 
We found that nurses' prevalence of mild depression and moderate to severe depression decreased by $7.47 \%$ and $4.35 \%$ between Stage 3 Stage 4 respectively. In contrast, doctors' prevalence of mild depression and moderate to severe depression decreased by $1.34 \%$ and $2.15 \%$ between Stage 3 and Stage 4 respectively, which can be seen that the reaction of nurses to the change factors between Stage 3 and Stage 4 is more intense (Fig. 6).

The mild depression of medical staff with different educational background showed great difference between the latter period of Stage 2 and Stage 3. During this period, graduate students' prevalence of mild depression increased from $14.29-19.42 \%$. However, the prevalence of mild depression decreased by $5.06 \%$ in undergraduate education background group and $2.03 \%$ in middle school education background group. The main difference of moderate and severe depression among medical staff with different educational background exists between Stage 3 and Stage 4 . During this period, the prevalence of moderate and severe depression of medical staff with undergraduate education and middle school education decreased, but the prevalence of moderate and severe depression of medical staff with graduate education increased by $3.99 \%$ (Fig. 7).

Between Stage 1 and the former period of Stage 2 (March 3 to March 5), only the prevalence of mild depression of medical staff with other marital status increased from 40-66.67\%, and the prevalence of mild depression of married and unmarried medical staff was alleviated. However, the prevalence of mild depression in medical staff with other marital status has been declining since then, while the prevalence of mild depression in married and unmarried medical staff increased by $15.15 \%$ and $6.26 \%$ respectively between two periods of Stage 2 (March 4 to March 17). The difference of moderate and severe depression among medical staff with different marital status should be paid attention to between the latter period of Stage 2 and Stage 3. During this period, the prevalence of moderate and severe depression of married medical staff increased from $2.46-5.86 \%$, while that of unmarried medical staff increased from $1.54-9 \%$ (Fig. 8).

\section{Analysis of the influencing factors of anxiety and depression}

2748 medical staffs were observed, applying multivariate regression model to explore the relevance between time and depression/anxiety of staffs. Variable 'Time' was taken as independent variable, depression/anxiety level of medical staffs were taken as dependent variables. Stage 1 (February 10-February 20) was taken as reference in multiple logistic regression, and $\mathrm{OR}(95 \% \mathrm{Cl})$ and $\mathrm{P}$ value were observed. Different models based on different adjustment were built to control the potential bias of confounder. In Model 1, we did single-factor analysis and any variables was adjusted. In Model 2, staffs' gender, age and occupation were adjusted. In Model 3, staffs' gender, age, occupation, marital status and educational background were adjusted.

In logistic regression analysis of depression in staffs, comparing with Stage 1 (February 10-February 20), the

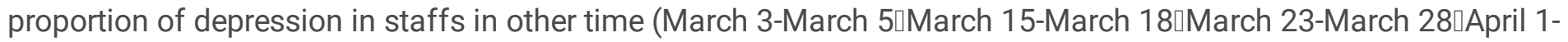
April 7) were all observed declined with different decrease. The decrease was observed statistically difference in the former period of Stage 2 (March 3-March 5) and the decrease of Stage 4 (April 1-April 7: after medical support teams got rest) were observed statistically significant difference. According to $P$ for trend, the decline of the proportion of depression in staffs as time goes by were observed statistically significant difference. Same trend was observed both in model 2 and model 3.

Similar trend was found in the result of logistic regression analysis of anxiety in staffs. Comparing with Stage 1

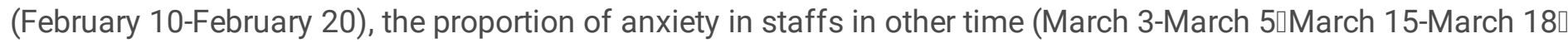
March 23-March 28\April 1-April 7) were all observed declined with different decrease. Decrease of Stage 4 (April 1April 7: after medical support teams got rest) were observed statistically significant difference. According to $P$ for 
trend, the decline of the proportion of anxiety in staffs as time goes by were observed statistically significant difference. Same trend was observed both in model 2 and model 3(Table 4, Table 5).

Table 4

Multivariate analysis results of anxiety

\begin{tabular}{|c|c|c|c|}
\hline Time & Model 1(cRR) & Model 2(aRR) & Model 3(aRR) \\
\hline $2.10-2.20$ & Ref & Ref & Ref \\
\hline $3.3-3.5$ & $0.276(0.142,0.537)$ & $0.279(0.143,0.545)$ & $0.278(0.142,0.544)$ \\
\hline $3.15-3.18$ & $0.25(0.167,0.374)$ & $0.251(0.167,0.376)$ & $0.249(0.166,0.374)$ \\
\hline $3.23-3.28$ & $0.302(0.239,0.381)$ & $0.293(0.23,0.371)$ & $0.293(0.231,0.372)$ \\
\hline $4.1-4.7$ & $0.159(0.123,0.206)^{\star \star \star}$ & $0.155(0.119,0.202)^{\star \star \star}$ & 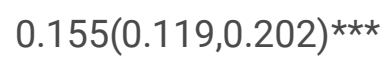 \\
\hline P-trend & $0.655(0.617,0.696)^{\star \star \star}$ & $0.650(0.611,0.692)^{\star \star \star}$ & 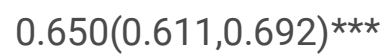 \\
\hline
\end{tabular}

Model 1: Single factor analysis. Model 2: Staffs' sex, age and occupation were adjusted. Model 3: Staffs' sex, age, occupation, marital status and educational background were adjusted. cRR:cursory Risk Ratio. aRR:adjusted Risk Ratio.

*P $<0.05,{ }^{* * P}<0.01$, ***P $<0.00010$

*2.10-2.20 is at the beginning of coronavirus epidemic in China,3.3-3. and 3.1-3.18 is in the period of coronavirus epidemic in China,Medical support teams backed in 3.23-3.28.4.1-4.7:After 14 days rest.

Table 5

Multivariate analysis results of depression

\begin{tabular}{|c|c|c|c|}
\hline Time & Model 1(cRR) & Model 2(aRR) & Model 3(aRR) \\
\hline $2.10-2.20$ & Ref & Ref & Ref \\
\hline $3.3-3.5$ & $0.151(0.072,0.317)^{\star}$ & $0.154(0.073,0.325)^{*}$ & $0.152(0.072,0.32) \star$ \\
\hline $3.15-3.18$ & $0.315(0.219,0.451)$ & $0.32(0.222,0.461)$ & $0.315(0.219,0.454)$ \\
\hline $3.23-3.28$ & $0.345(0.277,0.43)$ & $0.34(0.271,0.427)$ & $0.337(0.269,0.423)$ \\
\hline $4.1-4.7$ & $0.207(0.164,0.262)^{\star \star \star}$ & $0.205(0.161,0.261)^{\star \star \star}$ & 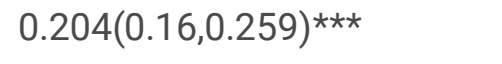 \\
\hline P-trend & 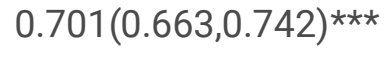 & $0.699(0.659,0.740)^{\star \star \star}$ & $0.698(0.658,0.739)^{\star \star \star}$ \\
\hline \multicolumn{4}{|c|}{$\begin{array}{l}\text { Model 1: Single factor analysis. Model 2: Staffs' sex, age and occupation were adjusted. Model 3: Staffs' sex, } \\
\text { age, occupation, marital status and educational background were adjusted. cRR:cursory Risk Ratio. aRR:adjustec } \\
\text { Risk Ratio. }\end{array}$} \\
\hline \multicolumn{4}{|c|}{${ }^{\star} \mathrm{P}<0.05$, ** $\mathrm{P}<0.01$, ${ }^{\star \star *} \mathrm{P}<0.0001$} \\
\hline \multicolumn{4}{|c|}{$\begin{array}{l}\text { * } 2.10-2.20 \text { is at the beginning of coronavirus epidemic in China,3.3-3. and } 3.1-3.18 \text { is in the period of } \\
\text { coronavirus epidemic in China,Medical support teams backed in 3.23-3.28.4.1-4.7:After } 14 \text { days rest. }\end{array}$} \\
\hline
\end{tabular}

\section{Discussion}

\section{Relationship between time and mental state of medical staff under epidemic situation}


According to the survey data shown in Table 2 and Table 3, considering the changes of mental health of medical workers in different stages of the epidemic, it is not difficult to find the following conclusions.

First of all, the prevalence of anxiety and depression peaked in Stage 1. The psychological status of surgical staff in the outbreak period (January 28 - February 29, 2020) was more severe than that in the non outbreak period (March 2 - March 21, 2020) ${ }^{[4]}$. Studies on SARS and Ebola also showed the same trend of anxiety and depression ${ }^{[5,6]}$. At the initial period of the epidemic, medical staff needs to urgently contact a large number of high-risk groups every day under the unknown danger of COVID-19, which aggravates their concern about their own infection and transmission to their families. And medical personnel must be equipped with full body protective equipment with negative pressure for more than 12 hours. In order to avoid infection when wearing protective equipment, staffs choose not to eat, drink or use the bathroom during working hours. Many of them are dehydrated by sweating too much, and some develop cystitis and rashes. Moreover, in the early stage of the pandemic, uncertain and inaccurate news related to covid-19 also catalyzed the panic situation to a large extent ${ }^{[7,8]}$. According to the experience of SARS in 2003 , it is necessary to arrange psychological doctors to provide temporary treatment for medical workers as soon as possible [9]. The front-line professionals are facing unprecedented serious and complex threats, and need systematic and professional psychological intervention and support ${ }^{[10]}$.

Secondly, between the former period of Stage 2 and Stage 3 of the epidemic, the prevalence of psychological problems increased or the existing psychological problems became more serious, although the prevalence has declined dramatically in the last period. Between the former period of Stage 2 and Stage 3, the medical staff knew that they were going to leave Hubei Province, be isolated and face their families ${ }^{[8]}$. According to previous researches, the most worrying thing is their families for medical staff ${ }^{[11]}$. Being afraid of spreading the virus to family members and 233 friends, high levels of anxiety and depression are unavoidable ${ }^{[8,12,13,14]}$. Medical workers should be encouraged to accept risks, avoid thinking, relax, and try to maintain a positive attitude ${ }^{[11]}$. In addition, governments at all levels in China also pay attention to the psychological status of medical staffs in this process. Intervention measures include shift system to reduce workload, providing life and family security support to ease the anxiety ${ }^{[15]}$.

\section{Characteristics of medical staff who are vulnerable in terms of psychological status under the epidemic situation}

Through the comparative analysis of data, we found that social demographic characteristics ,such as female, unmarried status, were the vulnerable characteristics of anxiety and depression of medical staff. Many studies have also confirmed that female ${ }^{[16-20]}$ can increase the exposure of medical staff to psychological problems in COVID-19 epidemic. Female individual perception regarding the seriousness of COVID-19 may contribute to the gender gap in anxiety and depression in this study. And unmarried medical staffs suffer more loneliness and less social support, while the lonely are proved to have more psychological problems ${ }^{[21,22]}$. The results in Table 2 and Table 3 show that the psychological problems of medical staff working outside Hubei Province are more serious than those in Hubei Province. Medical staff working outside Hubei Province were mainly investigated in Stage 1, a stage with the highest prevalence of mental problems, while all medical staff working in Hubei Province were investigated in Stage 3 and Stage 4. We still can't rule out that this conclusion is caused by the mixed influence of the epidemic development period, especially its serious conflict with previous conclusions and common sense. Therefore, following the conclusion of previous studies, we believe that the psychological problems of medical staff working in Wuhan during the epidemic period are more serious ${ }^{[17]}$. The medical staff working in Wuhan are faced with high risk of infection, overwork, depression, discrimination, weak protection against infection, isolation, exhaustion, lack of contact with their families and patients with negative emotions ${ }^{[15]}$. 
Therefore, we suggest that the supervision and intervention of psychological problems for female, young medical workers and unmarried medical workers should be the priority areas of mental health care for anti epidemic medical workers, and the psychological supervision and intervention for these people should run through the whole process of mental health care.

\section{The change trend of psychological status of different groups at a certain stage}

The whole population needs to be paid attention to at some specific stages (Stage 1, the latter period of Stage 2, Stage 3), and some subgroups in individual stages also need more attention.

In Stage 2 (the development stage of the epidemic), we found that more medical workers with other marital status (divorced, separated, widowed) developed depression, and even their depression level became serious. A study on workforce returning to work (February 24-25, 2020) also confirmed that people with other marital status (divorced, separated, widowed) had significantly higher anxiety and depression ${ }^{23}$. Adequate social support provided by partner or spouse is a protective factor of mental health. In the early stage of the rapid development of the epidemic, social support as a buffer stress response ability is helpful to reduce anxiety and depression for medical workers in the face of epidemic challenges. On the contrary, those with other marital status without social support from their spouses lack the ability of facing stress.

In Stage 3, the anxiety level of nurses deteriorated, while the anxiety of doctors was relieved. This phenomenon may be due to the fact that in China, nurses are mainly female, as is the case in the sample. Stage 3 is the returning time from Hubei Province for the medical team, and female may consider more at this stage. First of all, as caregivers of families, women are more worried about infected family members. Moreover, much psychological burden on the infectious risk make them easier to be trapped in the psychological problems. Nursing managers should make learning plan of covid-19 epidemic situation ${ }^{[24]}$. Nurse leaders should guide nurses to adjust their psychological state scientifically, arrange leisure activities and relaxation training properly, and help employees to reduce pressure $[25,26]$

As is described in Fig. 3 and Fig. 7, in Stage 3 and Stage 4, the prevelance of depression and anxiety of graduates increased respectively, showing the opposite trend of the medical staff with other education background. Previous

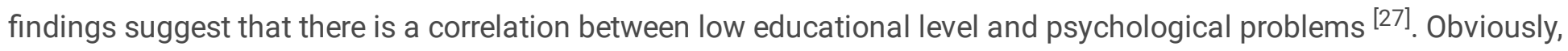
our results do not conform to previous perceptions. We believe that the reality should be that during the returning time from Hubei Province, more depression and anxiety will happen to people with low education level. This is because perception with medical expertise may help break COVID-19's sense of mystery, so as to reduce the panic of infected family members, partners and spouses. Based on this conjecture, we believe that systematic pre-training for the COVID-19 epidemic can help reduce unnecessary psychological problems ${ }^{[24]}$.

\section{Abbreviations}

\begin{tabular}{|ll|}
\hline Meaning & Abbreviations \\
\hline Corona Virus Disease 2019 & COVID-2019 \\
\hline Somatization Symptom Checklist & SSS \\
\hline Self rating scale for post-traumatic stress disorder & PCL-C \\
\hline & \\
\hline
\end{tabular}




\section{Declarations}

Ethics approval and consent to participate: The experimental protocol was established, according to the ethical guidelines of the Helsinki Declaration and was approved by the Human Ethics Committee of Kunming Medical University. Written informed consent was obtained from individual participants (adults).

Consent for publication: Not applicable.

Availability of data and materials: The datasets generated and/or analysed during the current study are not publicly available due to being applied in the following non-public research but are available from the corresponding author on reasonable request.

Competing interests: The authors declare that they have no competing interests.

Funding: This work was supported by Yunnan Province Science and Technology Major Project (study on Corona Virus Disease 2019 transmission dynamics model in Yunnan province and the evaluation of the effectiveness of the prevention and treatment measures).

Authors' contributions: Y. Z, C. L and X. Z were major contributors in writing the manuscript. All authors read and approved the final manuscript. L. X and W. M were responsible for data analysis and collection. D. Y and Y. L designed the research framework and revised the manuscript.

Acknowledgements: ZhouYanjiøChengyu Li and Xiyu Zhang are the co-first authors of this paper. All authors have made a substantial contribution to this submission.

\section{References}

1. Maunder, R. G., Lancee, W. J., Rourke, S., Hunter, J. J., Goldbloom, D., Balderson, K., ... Fones, C. S. L. (2004). Factors Associated With the Psychological Impact of Severe Acute Respiratory Syndrome on Nurses and Other Hospital Workers in Toronto. Psychosomatic Medicine, 66(6), 938-942. doi:10.1097/01.psy.0000145673.84698.18

2. Bai Y, Lin CC, Lin CY, Chen JY, Chue CM, Chou P. Survey of stress reactions among health care workers involved with the SARS outbreak. Psychiatr Serv. 2004;55(9):1055-7.

3. Zhu J, Sun L, Zhang L, Wang H, Fan A, Yang B, Li W and Xiao S (2020) Prevalence and Influencing Factors of Anxiety and Depression Symptoms in the First-Line Medical Staff Fighting Against COVID-19 in Gansu. Front. Psychiatry 11:386. doi: 10.3389/fpsyt.2020.00386

4. Xu, J., Xu, Q., Wang, C., \& Wang, J. (2020). Psychological status of surgical staff during the COVID-19 outbreak. Psychiatry Research, 112955. doi:10.1016/j.psychres.2020.112955

5. Liao Q, Cowling BJ, Lam WW, Ng DM, Fielding R (2014) Anxiety, worry and cognitive risk estimate in relation to protective behaviors during the 2009 influenza A/H1N1 pandemic in Hong Kong: ten cross-sectional surveys.

BMC Infect Dis 14:169. https://doi.org/10.1186/1471-2334-14-169

6. Van Bortel T, Basnayake A, Wurie F, Jambai M, Koroma AS, Muana AT, Hann K, Eaton J, Martin S, Nellums LB (2016) Psychosocial effects of an Ebola outbreak at individual, community and international levels. Bull World Health Organ 94(3):210-214. https://doi.org/10.2471/blt.15.158543

7. Huckins, J. F., daSilva, A. W., Wang, W. C., Hedlund, E., Rogers, C., Nepal, S. K.,.. . Campbell, A. T. (2020). Mental Health and Behavior of College Students During the Early Phases of the COVID-19 Pandemic: Longitudinal 
Smartphone and Ecological Momentary Assessment Study. Journal of Medical Internet Research, 22(6), 13. doi:10.2196/20185

8. Wang C, Pan R, Wan X, Tan Y, Xu L, Ho CS, Ho RC (2020) Immediate Psychological Responses and Associated Factors during the Initial Stage of the 2019 Coronavirus Disease (COVID-19) Epidemic among the General Population in China. Int J Environ Res Public Health. https://doi.org/10.3390/ijerph17051729

9. Maunder R, Hunter J, Vincent L, et al. The immediate psychological and occupational impact of the 2003 SARS outbreak in a teaching hospital. CMAJ: Canadian Medical Association journal1/4journal de l'Association medicale canadienne 2003; 168: 1245-1251. https://www. ncbi.nlm.nih.gov/pubmed/12743065 (accessed 31 March 2020).

10. Zaka, A., Shamloo, S. E., Fiorente, P., \& Tafuri, A. (2020). COVID-19 pandemic as a watershed moment: A call for systematic psychological health care for frontline medical staff. Journal of Health Psychology, 135910532092514. doi:10.1177/1359105320925148

11. Dong, Z.-Q., Ma, J., Hao, Y.-N., Shen, X.-L., Liu, F., Gao, Y., \& Zhang, L. (2020). The social psychological impact of the COVID-19 epidemic on medical staff in China: a cross-sectional study. European Psychiatry, 1-22. doi:10.1192/j.eurpsy.2020.59

12. Grace SL, Hershenfield K, Robertson E, Stewart DE. The occupational and psychosocial impact of SARS on academic physicians in three affected hospitals. Psychosomatics 2005; 46(5):385-91.

https://doi.org/10.1176/appi.psy.46.5.385

13. Chen Q, Liang M, Li Y, Guo J, Fei D, Wang L, et al. Mental health care for medical staff in China during the COVID-19 outbreak. Lancet Psychiatry. 2020;7(4): e15-e16.

14. Adams JG, Walls RM. Supporting the Health Care Workforce During the COVID-19 GlobalEpidemic. JAMA. 2020. https://doi.org/10.1001/jama.2020.3972

15. Kang, L., Li, Y., Hu, S., Chen, M., Yang, C., Yang, B. X., ... Liu, Z. (2020). The mental health of medical workers in Wuhan, China dealing with the 2019 novel coronavirus. The Lancet Psychiatry. doi:10.1016/s22150366(20)30047-x

16. Kang L, Ma S, Chen M, et al. Impact on mental health and per - 53. ceptions of psychological care among medical and nursing staff in Wuhan during the 2019 novel coronavirus disease outbreak: A cross-sectional study. Brain Behav Immun 2020; pii: S0889- 1591(20)30348-2.

17. Lai J, Ma S, Wang Y, et al. Factors associated with mental health 51 . outcomes among health care workers exposed to Coronavirus Disease 2019. JAMA Netw Open 2020; 3: e203976.

18. Huang JZ, Han MF, Luo TD, Ren AK, Zhou XP. Mental health 52. survey of 230 medical staff in a tertiary infectious disease hospital for CoViD-19. Chin Ind Hyg Occup Dis 2020; 38: E001

19. Wang, Y. N., Di, Y., Ye, J. J., \& Wei, W. B. Study on the public psychological states and its related factors during the outbreak of coronavirus disease 2019 (COVID-19) in some regions of China. Psychology Health \& Medicine, 10. doi:10.1080/13548506.2020.1746817

20. Varshney, M., Parel, J. T., Raizada, N., \& Sarin, S. K. (2020). Initial psychological impact of COVID-19 and its correlates in Indian Community: An online (FEEL-COVID) survey. PLOS ONE, 15(5), e0233874.

doi:10.1371/journal.pone.0233874

21. Robertson E, Hershenfield K, Grace SL, Stewart DE. The psychosocial effects of being quarantined following exposure to SARS: a qualitative study of Toronto health care workers. Can J Psychiatry. 2004; 49(6):403-7. https://doi.org/10.1177/070674370404900612 
22. Tam CW, Pang EP, Lam LC, Chiu HF. Severe acute respiratory syndrome (SARS) in Hong Kong in 2003: stress and psychological impact among frontline healthcare workers. Psychol Med. 2004; 34(7):1197-204. https://doi.org/10.1017/s0033291704002247

23. Tan, W., Hao, F., Mclntyre, R. S., Jiang, L., Jiang, X., Zhang, L., ... Tam, W. (2020). Is Returning to Work during the COVID-19 Pandemic Stressful? A Study on Immediate Mental Health Status and Psychoneuroimmunity Prevention Measures of Chinese Workforce. Brain, Behavior, and Immunity. doi:10.1016/j.bbi.2020.04.055

24. Wu, J., Wu, X., Wu, F., Dia, Y., Dechun, C. \&Gong, X. (2020). Survey of sleep quality of clinic-al front-line nurses and its influencing factors in the fight against new coronavirus pneumonia. Nursing Research, 344, 558-562. Retrieved from http://kns.cnki.net/kcms/detai l/14.1272.r.20200 214.1136.004.html

25. $10.1111 /$ jonm. 13014

26. Labrague, L. J., \& de los Santos, J. (2020). COVID-19 anxiety among frontline nurses: predictive role of organisational support, personal resilience and social support. Journal of Nursing Management. doi:10.1111/jonm.13121

27. $10.1002 /$ brb3.1818

\section{Figures}

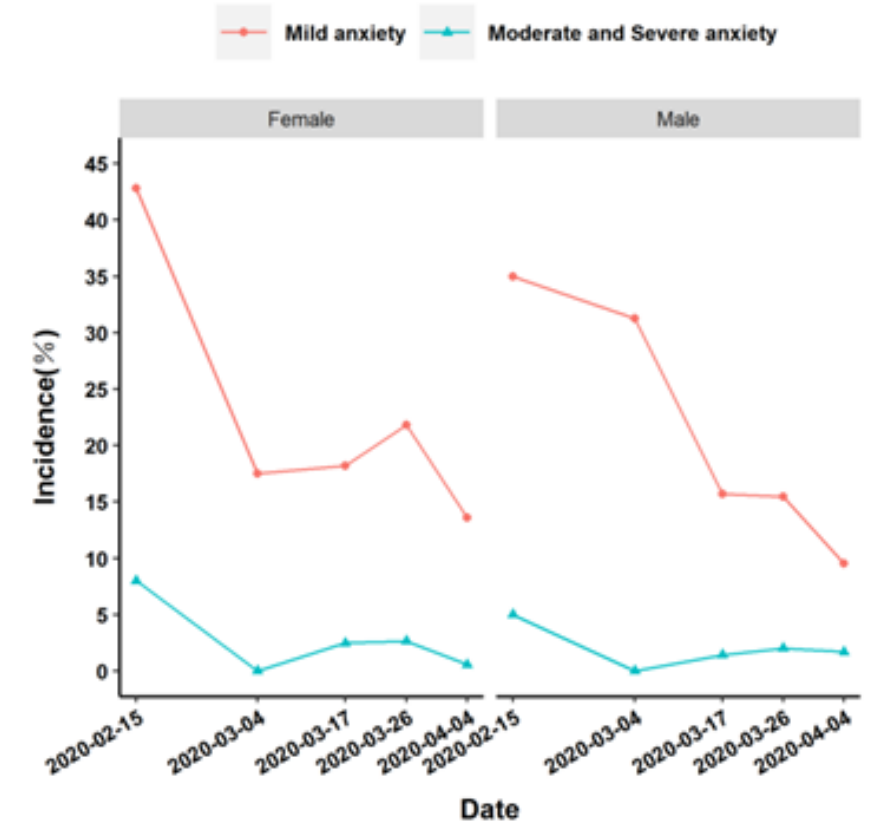

Figure 1

Influence of gender on anxiety of medical staff in different periods of epidemic 


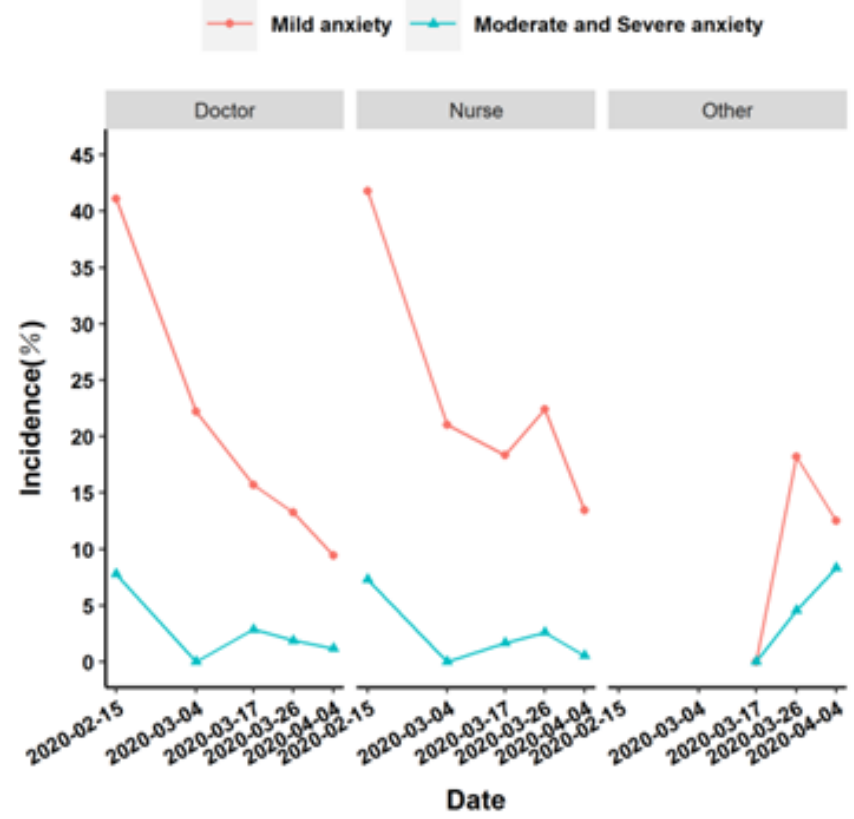

Figure 2

Influence of occupation on anxiety of medical staff in different periods of epidemic

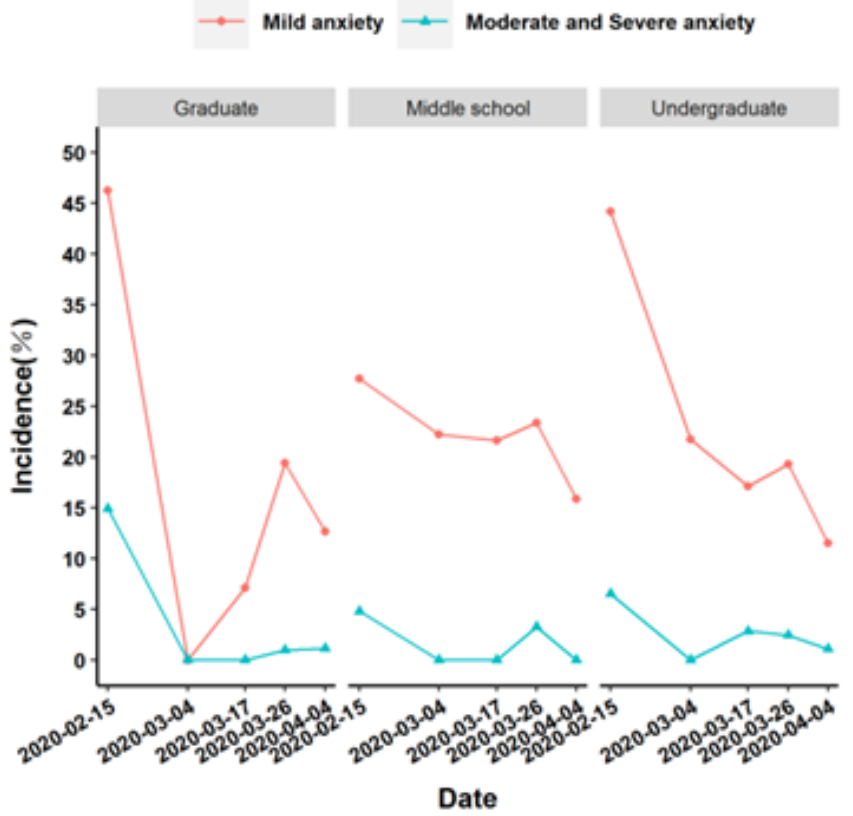

\section{Figure 3}

Influence of educational background on anxiety of medical staff in different periods of epidemic 


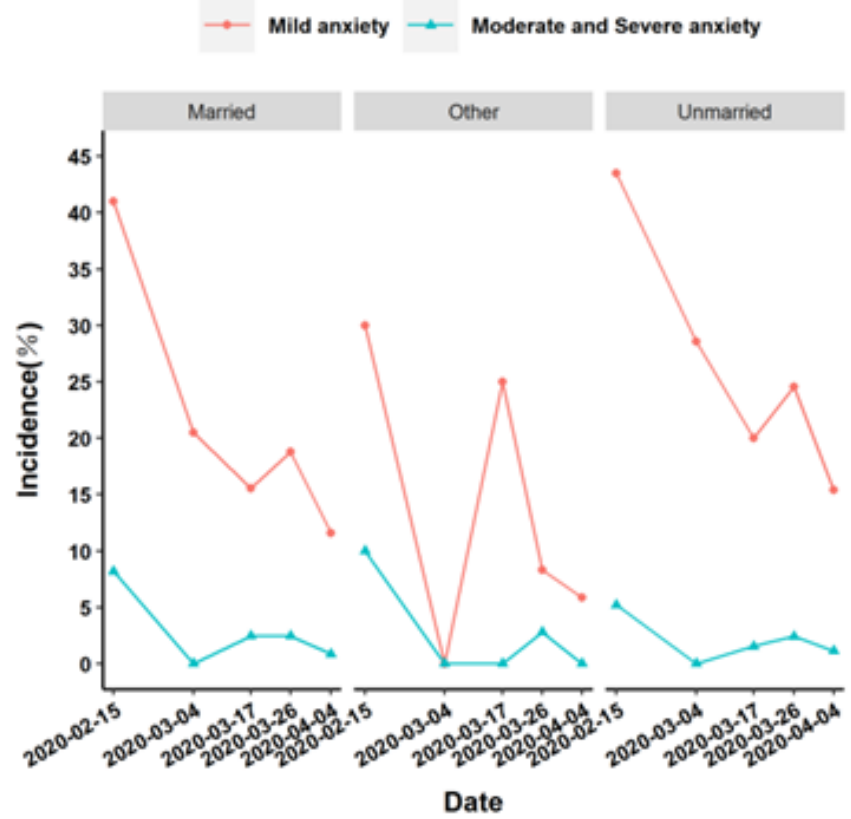

Figure 4

Influence of marriage on anxiety of medical staff in different periods of epidemic

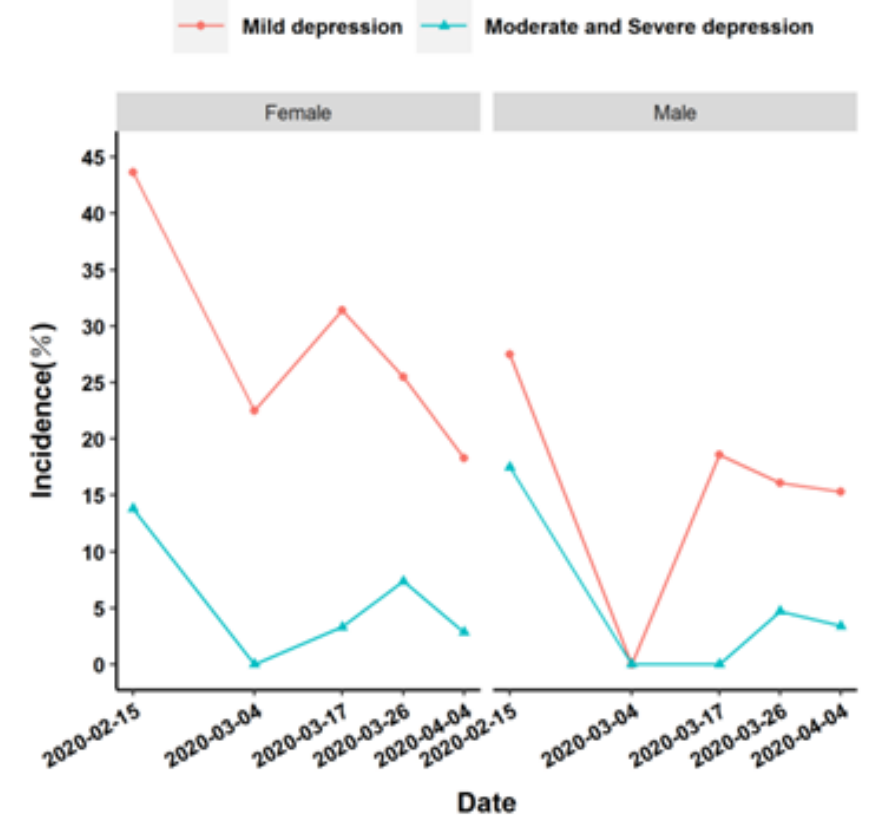

Figure 5

Influence of gender on depression of medical staff in different periods of epidemic 


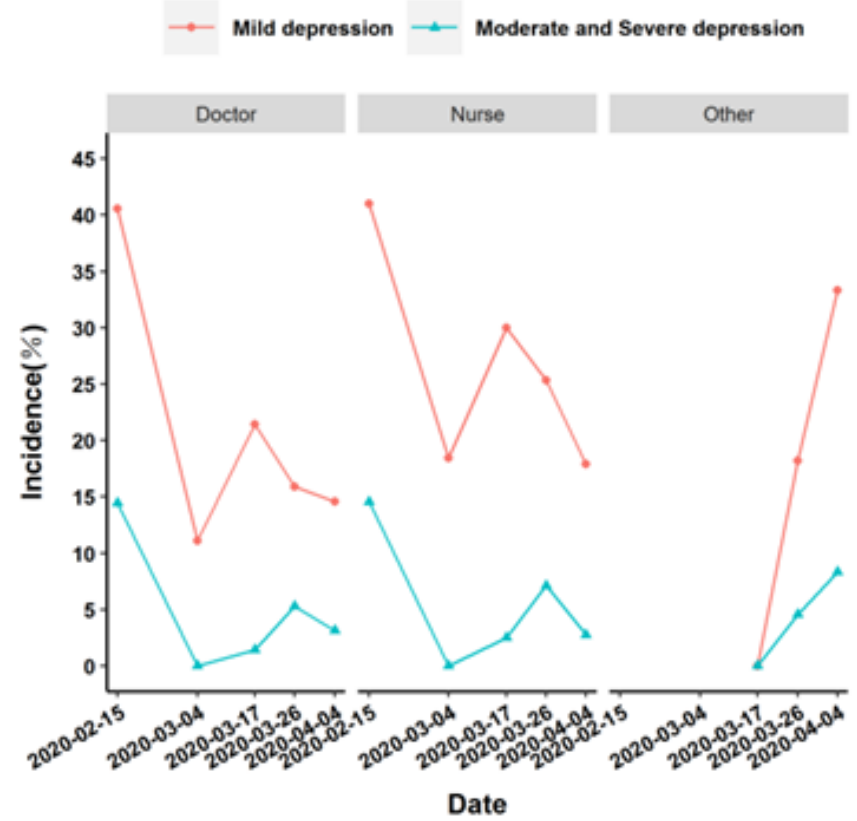

Figure 6

Influence of occupation on depression of medical staff in different periods of epidemic

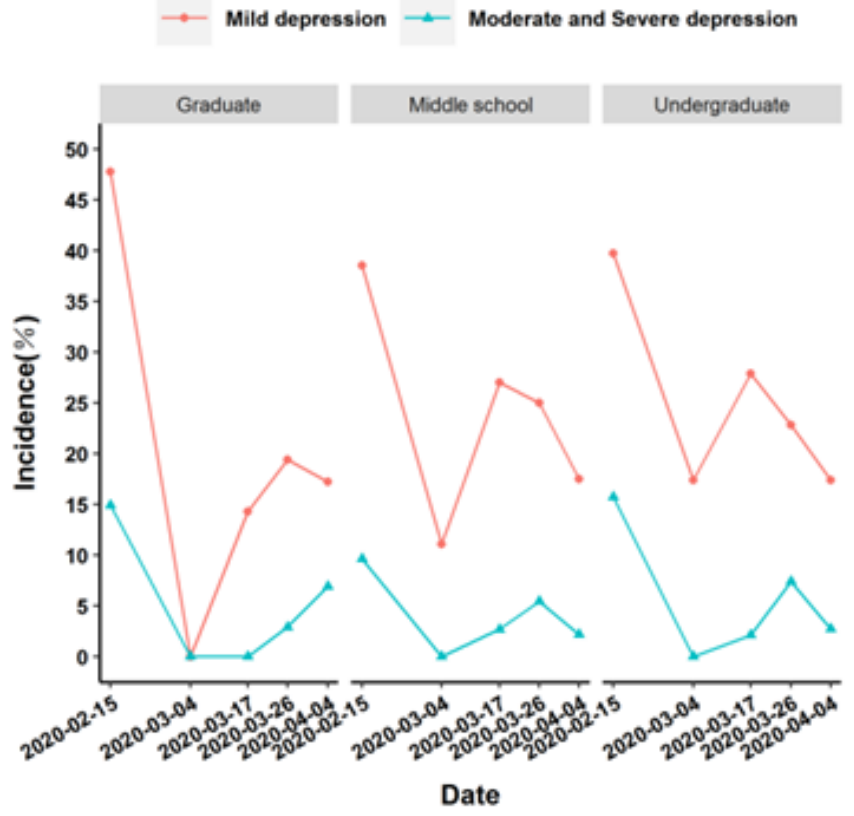

\section{Figure 7}

Influence of educational background on depression of medical staff in different periods of epidemic 


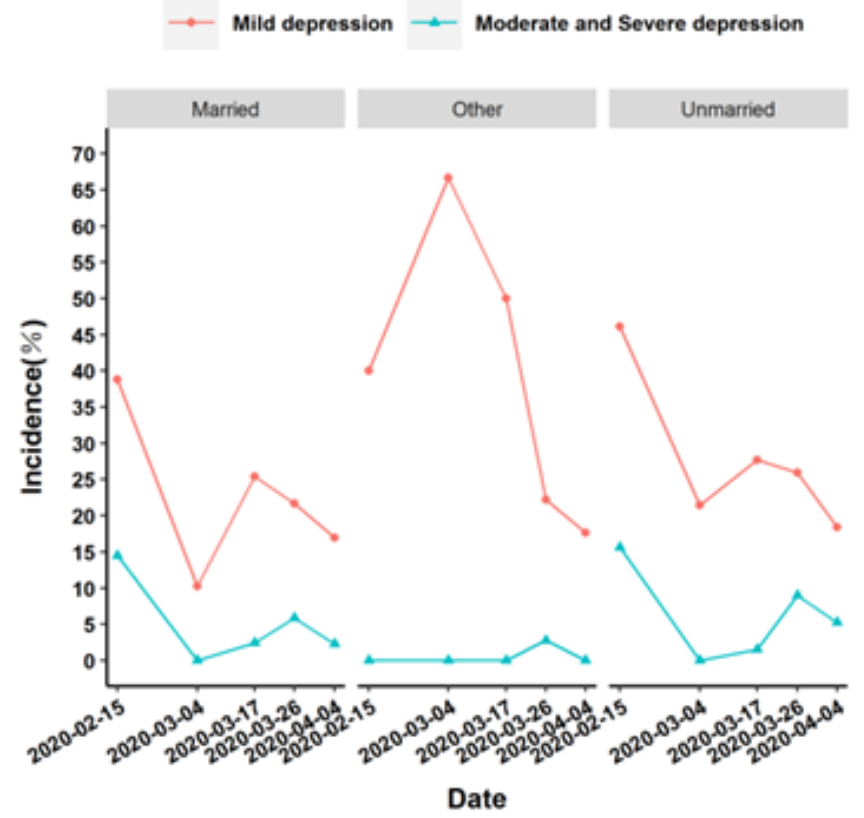

\section{Figure 8}

Influence of marrige on depression of medical staff in different periods of epidemic 